\title{
Dread Aversion and Economic Preferences
}

\author{
Christopher Dawson ${ }^{1}$ \\ Samuel G. B. Johnson 1,2,3
}

${ }^{1}$ University of Bath School of Management, Division of Marketing, Business, \& Society 2 University of Warwick, Department of Psychology

${ }^{3}$ University College London, Centre for the Study of Decision-Making Uncertainty

Corresponding Author: Christopher Dawson

Email for Correspondence: $\quad$ c.g.dawson@bath.ac.uk

Word Count: $\quad 7,877$ (main text)

Last Revised: $\quad 8$ April 2021 (draft)

Note: This is a working paper; it has not been peer-reviewed.

Acknowledgements: The authors would like to thank participants at the Applied Economics Seminar Series at the University of Bath, David de Meza, and Paul L. Baker for helpful discussion. 


\begin{abstract}
We are often preoccupied with the future, experiencing dread at the thought of future misery and savoring the thought of future pleasure. Prior lab studies have found that these anticipatory emotions influence decision-making. In this article, using a novel approach, we use economic survey data to estimate individual differences in anticipatory emotions, finding that the tendency to feel displeasure (dread) from anticipating future losses outweighs the pleasure (savoring) from anticipating equal gains - that is, people are dread-averse. We then relate anticipatory emotions to key economic preferences, finding that more dread-averse people are more risk-averse (because they obtain more disutility from contemplating downside risk) and more impatient (because they want to minimize the time spent contemplating risks). We conclude by considering how dread aversion can provide novel explanations for a variety of intertemporal and risky choice phenomena. Dread aversion explains why people are both risk-averse and impatient and provides suggestive evidence as to why these traits are linked.
\end{abstract}

Keywords: Anticipatory emotions, Time preferences, Risk preferences, Behavioral economics 
"Depend upon it, sir, when a man knows he is to be hanged in a fortnight, it concentrates his mind wonderfully."

- Samuel Johnson

(from Boswell's Life of Johnson)

When deciding to bet $\$ 100$ on red or black at the roulette table, we are meant to assess the likelihood of losing alongside a subjective estimate of how bad that loss would feel. However, if we make the bet, and the roulette wheel starts spinning, anticipatory emotions such as dread arise as our minds focus on the outcomes of the gamble. This feeling of dread is endured until the roulette wheel slows and the outcome of the uncertainty is resolved. This process, whereby decisions involve both risk and delay, is common for most decisions we face, whether that's starting a new business or choosing a spouse. The consequences of our choices rarely materialize immediately but, more often than not, unfold only with time.

In this article, we focus on individual differences in anticipatory emotions and how these differences predict both risk and time preferences. First, we find that anticipating future negative events (dread) is more potent than anticipating their positive counterparts (savoring); that is, people are dread averse. Second, dread aversion is associated with both risk-aversion and impatience. For a dread averse gambler at the roulette table, the expected disutility of anticipatory emotions makes the gamble less attractive. And if the bet is placed, the gambler pleads for the roulette wheel to slow down so that the uncertainty can be resolved. Thus, dread aversion provides the missing psychological link between time- and risk-preferences.

Keeping in mind the roulette table, we distinguish three kinds of emotions that influence decision-making based on their temporal profile (see Baumgartner, Pieters, and Bagozzi 2008; Loewenstein and Lerner 2003). Consider a choice made at time $T_{0}$ which will deliver a good or bad outcome at $T_{2}$. First, we feel reactive emotions in response to the resolved outcome of our decision, such as the (dis)pleasure of experienced gains and losses. In Figure 1, reactive emotions occur at $T_{2}$ in response to realized good or bad outcomes (e.g., money gained or lossed at roulette). Second, we feel anticipatory emotions before an outcome occurs, which are generated from mental imagery of the expected consequences of the risky decision. Specifically, we experience dread in response to an imagined bad outcome or savoring in response to an imagined good outcome occurring at $T_{2}$ (Loewenstein 1987). Anticipatory emotions occur at $T_{1}$ in Figure 1 (e.g., while the roulette wheel is spinning). Third, we make forecasts of our emotions at $T_{0}$ (e.g., when placing bets); these are expected emotions (also known, confusingly, as anticipated emotions). Since both reactive and anticipatory emotions occur after the decision itself is made, these emotions influence choice only through the way they are expected at $T_{0}$ (Mellers, Schwartz, and Ritov 1999). Note that 
some models (e.g., Loewenstein et al., 2001) do not distinguish between anticipatory emotions (experienced at $T_{1}$ ) with expected anticipatory emotions (forecasts at $T_{0}$ of experiences at $T_{1}$ ), which will prove central to our theory.

\section{Expected}

Emotions

\section{Anticipatory \\ Emotions}

\section{Reactive}

Emotions

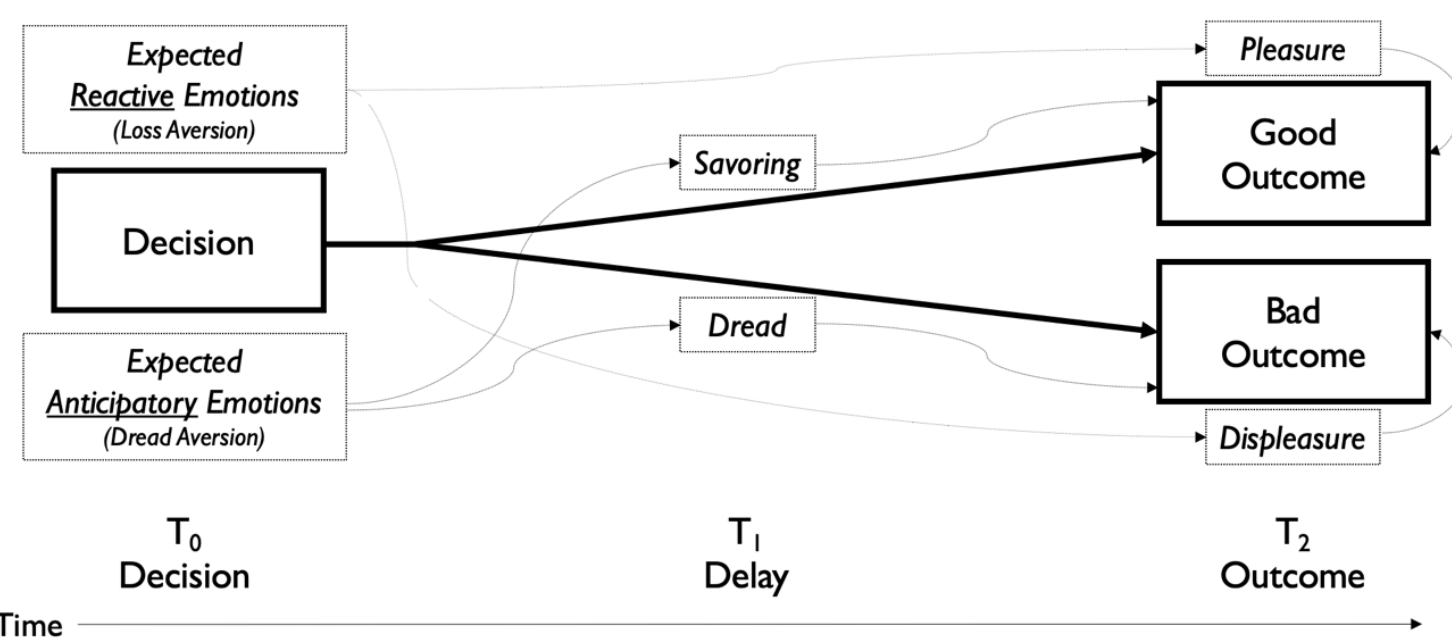

Figure 1. Distinctions among expected, anticipatory, and reactive emotions along the timecourse of decision-making.

As examples of expected reactive emotions, people avoid options at $T_{0}$ that they expect to lead to negative reactive emotions at $T_{2}$ such as regret or disappointment (Loomes and Sugden, 1982). Famously, people are loss-averse (Kahneman and Tversky 1979) — they assume (at $T_{0}$ ) that the displeasure of losses is greater than the pleasure of equivalent gains (at $T_{2}$ ). Interestingly, loss aversion has been argued to be an affective-forecasting error: Forecasts of loss aversion are large, whereas the realized emotional impact of losses and gains are more symmetric (Kermer et al., 2006).

Expected anticipatory emotions have been studied primarily in the context of intertemporal choice (an exception is Caplin and Leahy 2001). Whereas most behavioral models aim to explain why people undervalue future outcomes relative to standard neoclassical models (Laibson 1997; Loewenstein and Prelec 1991), there are other situations when we value the future too much. Loewenstein (1987) showed that discount rates can be negative when future sources of (dis)utility are particularly vivid. For example, Loewenstein's participants were willing to pay more to receive a kiss from a movie star in 3 days than 1 day, and to pay more to avoid an electric shock in 1 year than in 3 days. Loewenstein assumed that this occurs because people gain or lose utility not only from the consumption of these events (associated with reactive emotions) but also from imagining them (associated with anticipatory emotions). Whereas consumption utility will only be attained in the future, and hence is steeply discounted, (dis)utility from savoring or dread can be experienced 
continuously from the time of the decision until the event occurs. Thus, delaying the kiss creates utility from savoring that more-than-offsets the discounting of the kiss's consumption utility, while experiencing the shock sooner avoids disutility from dread that more-than-offsets the discounting of its consumption disutility. Many subsequent studies confirm this basic picture (Berns et al. 2006; Harris, 2011; Iigaya et al. 2016; Lovallo and Kahneman 2000; Story et al. 2013, 2015).

However, dread and savoring are not equally powerful. The disutility from imagining the negative event is greater than the utility of imagining a comparable positive event (Molouki et al. 2019): We dub this asymmetry dread aversion. ${ }^{1}$ There are two mutually inclusive possibilities as to why dread aversion can arise. First, since people are loss-averse, anticipatory emotions at $T_{1}$ might simply reflect the greater psychological disutility of bad outcomes at $T_{2}$. Just as dread would be greater for a $\$ 200$ than for a $\$ 100$ loss, dread for a $\$ 100$ loss (psychologically valued at $\$ 200$ due to loss-aversion) would be greater than savoring for a $\$ 100$ gain (valued at $\$ 100)$. Second, imagining a positive outcome is emotionally mixed, whereas imagining a negative outcome is purely negative (Hardisty and Weber 2020; Nowlis et al. 2004). Whereas we dread an upcoming electric shock, we experience both savoring and impatience over an upcoming vacation. For example, most people prefer to resolve lotteries sooner as the magnitude of the payoff increases, suggesting that savoring competes (and sometimes loses) to other emotions such as impatience (Ganguly and Tasoff 2017).

In this article, we argue that dread aversion explains a fundamental puzzle about economic preferences: Why risk- and time-preferences are strongly inter-related. Standard models of riskand time-preferences in both neoclassical and behavioral economics treat these as separate dimensions of behavior. But several lines of thinking suggest they are related. First, theorists have noted that the future is inherently uncertain, suggesting that risk attitudes are likely to affect intertemporal choices (Dasgupta and Maskin 2005; Epper and Fehr-Duda 2018). Second, there is empirical support for this relationship: Risk- and time-preferences are subject to some of the same anomalies in experiments (Epper and Fehr-Duda 2018; Prelec and Loewenstein 1991) and individuals who are more risk-averse seem to be more impatient (e.g., Anderhub et al. 2003; Dean and Ortoleva 2019), although evidence on this point has not been univocal (e.g., among adolescents; Sutter et al. 2013). Moreover, time-preferences shift when risk is introduced, undermining the idea that these preferences are independent (Anderson and Stafford 2009; Hardisty and Pfeffer 2017; Keren and Roelofsma 1995). Finally, studies of preference elicitation have found that eliciting risk- and time-preferences simultaneously leads to more plausible

\footnotetext{
${ }^{1}$ The term 'Dread Aversion' seems to have originated in a recent working paper (Dawson and de Meza 2018). Here, the authors discuss the asymmetry between dread and savouring and its role in encouraging optimism.
} 
discount rates because myopic time preferences are partly due to risk-aversion (Andersen et al. 2008; Andreoni and Sprenger 2012).

But there is little empirical work examining why risk- and time-preferences are intertwined. We propose that dread-aversion provides this missing link. In the real world, many decisions are both risky and the payoffs are delayed. For example, when we decide what job to take, where to live, or who to marry, we will not know the consequences for months or years; likewise, many (if not most) business decisions are both uncertain and delayed. When decisions involve both risk and delay, anticipatory emotions potentially play a powerful role, as we are licensed to imagine both good and bad outcomes until the outcome is resolved (Golman et al. 2020). To the extent that people are dread-averse, their disutility from imagining the bad outcomes will outweigh the utility from imagining the good outcomes. This implies a link between risk-aversion and impatience. Dread-averse people will experience present disutility from future uncertainty, and this disutility will be proportional to the time delay until the uncertainty is resolved. If more dread-averse people correctly forecast these anticipatory emotions, they will be more risk-averse and more impatient: More risk-averse because avoiding risks minimizes disutility from contemplating possible negative outcomes, and more impatient because resolving uncertainty faster minimizes the time-period spent experiencing disutility from contemplating negative outcomes.

A few lab studies are broadly consistent with these predictions. As an example on the savoring side, although most people prefer to find out the outcome of a lottery immediately, a minoritywho are especially optimistic about the outcome and are more prone to experiencing the "thrill" of waiting - prefer delayed resolution (Kocher, Krawczyk, and van Winden 2014). On the dread side, there is experimental evidence that using emotion regulation strategies—such as reappraising emotions to more adaptively manage their impact on decision-making-decreases risk-aversion (Heilman et al. 2010), implicating a direct causal link between emotional cognition and risky choice. This fits with the broader association between neuroticism (emotional instability) and risk-aversion as personality traits (Borghans et al. 2009).

However, the primary obstacle to amassing large-scale evidence relating anticipatory emotions to economic preferences is measuring anticipatory emotions in economic survey data. Here, we develop a novel approach to jointly estimating anticipatory savoring and dread across a nationally representative sample from the UK. To our knowledge, this study is the first to elicit individual levels of dread and savoring and relate them to time and risk preferences. 


\section{Theory}

To see more formally why expected anticipatory emotions can explain the link between risk and time preferences, consider a decision made at $T_{0}$ whether to accept a gamble that will be resolved at $T_{2}$. We follow prior models (Caplin and Leahy 2001; Loewenstein 1987), in assuming that the agent aims to maximize expected psychological utility, $U=U_{A}+U_{C}$, where $U_{C}$ is the expected consumption utility — expected pleasure or displeasure at the actual outcome at $T_{2}$ —and $U_{A}$ is expected anticipatory utility —expected dread or savoring experienced at $T_{1}$. For example, if the agent is deciding whether to take a coin toss gamble where heads pays $+\$ 100$ and tails costs $-\$ 100$, we assume this will depend on the agent's forecasts about both the reactive emotions associated with each potential $T_{2}$ outcome and the anticipatory emotions associated with uncertainty at $T_{1}$. For the purpose of the model, we are agnostic as to whether expectations of $U_{A}$ and $U_{C}$ utility are rational; for example, we assume that people forecast loss aversion, but this could be an affective forecasting error if people actually experience losses and gains symmetrically (Kermer et al. 2006).

Beginning with risk preferences, consider a gamble offering the monetary payoffs $\left(x_{1}, \ldots, x_{n}\right)$ with probabilities $\left(p_{1}, \ldots, p_{n}\right)$. We make the standard assumption that expected consumption utility $U_{C}$ is given by the psychological value of each payoff, $v\left(x_{i}\right)$, weighted by a function of its probability $\pi\left(p_{i}\right)$ :

$$
U_{C}=\sum v\left(x_{i}\right) \pi\left(p_{i}\right)
$$

We assume that $v\left(x_{i}\right)$ is increasing, that $v(0)=0$, and, following prospect theory (Kahneman and Tversky 1979), that people are loss-averse: if $x_{i}<0$, then $v\left(x_{i}\right)=-\lambda v\left(-x_{i}\right)$ for lossaversion parameter $\lambda>1$. Prospect theory also assumes that $v\left(x_{i}\right)$ is concave for gains and convex for losses and that $\pi\left(p_{i}\right)$ is increasing but nonlinear, with people overweighting small probabilities and underweighting large probabilities.

Even without adding in anticipatory utility, this model implies some risk-aversion. For our coin flip example, assume for simplicity that for $x_{i}>0, v\left(x_{i}\right)=x_{i}$, that $\pi\left(p_{i}\right)=p_{i}$, and that $\lambda=2$. The expected consumption utility would be $(0.5)(100)+(0.5)(2)(-100)=-50$, so the agent would not take the gamble. This is entirely governed by the loss-aversion parameter: For any $\lambda>$ 1 , the agent would be risk-averse, while for a hypothetical agent for whom gains loomed larger than losses, $\lambda<1$, the agent would be risk-seeking. 
We now add $U_{A}$, the expected utility from anticipation. If $\phi$ reflects the expected anticipatory (dis)utility at $T_{1}$ associated with contemplating a possible future event at $T_{2}$, then we simply add up these expected anticipatory utilities for each outcome $i$ :

$$
U_{A}=\sum \phi\left(v\left(x_{i}\right)\right)
$$

We assume that $\phi$ is an increasing function of $v\left(x_{i}\right)$, that $\phi(0)=0$, and that for $v\left(x_{i}\right)<0$, $\phi\left(v\left(x_{i}\right)\right)=-\sigma \phi\left(-v\left(x_{i}\right)\right)$ for dread-aversion parameter $\sigma>1$; that is, anticipating negative outcomes has greater psychological impact than anticipating equivalent positive outcomes. ${ }^{2}$

This model reflects both rationales for dread-aversion. First, even if $\phi\left(v\left(x_{i}\right)\right)$ is a linear function of $v\left(x_{i}\right)$ with $\sigma=1$, then loss-aversion still implies that $\left|\phi\left(-v\left(x_{i}\right)\right)\right|>\left|\phi\left(v\left(x_{i}\right)\right)\right|$ since $\left|v\left(-x_{i}\right)\right|>\left|v\left(x_{i}\right)\right|$. That is, contemplating losses is more painful than contemplating gains is pleasurable in part because the expected reactive emotions associated with losses are stronger. This rationale does not assume that dread itself is a stronger emotion than savoring, but instead assumes that the amount of dread over losing $x_{i}$ would be greater than the amount of savoring over gaining $x_{i}$, since loss-aversion says that the disutility of a $x_{i}$ loss is greater than the utility of a $x_{i}$ gain. Second, we additionally allow negative anticipatory emotions to be more powerful than positive ones $(\sigma>1)$, because anticipating negative events is purely aversive, whereas anticipating positive events mixes positive (savoring) and negative (impatience) emotions (Nowlis et al. 2004). These two effects independently contribute to dread-aversion.

In this model, the utility of gambles is lower as $\lambda$ and $\sigma$ increase, meaning that risk-aversion increases with both loss-aversion and dread-aversion. Specifically, when at least one of the $x_{i}$ 's is negative, this implies that $U$ decreases as a function of $\lambda$ and $\sigma$, since $\lambda$ and $\sigma$ only appear in the negative terms, $x_{i}<0$, of the expressions for both $U_{A}$ and $U_{C}$. For our coin flip example, assume that for $x_{i}>0, \phi\left(v\left(x_{i}\right)\right)=\frac{1}{20} v\left(x_{i}\right)$ and that $\sigma=3$. That is, we assume that the utility of savoring a gain is one-twentieth of the utility that would be realized from that gain and that dread is three times more powerful than savoring. Then $U_{A}=\sum \phi\left(v\left(x_{i}\right)\right)=\left(\frac{1}{20}\right)(100)+$

\footnotetext{
${ }^{2}$ For simplicity, we assume that $\phi$ depends only on $v\left(x_{i}\right)$ and not on the probabilities of each outcome $p_{i}$, since affective reactions to imagined events depend mainly on their magnitudes rather than their probabilities (Loewenstein et al. 2001; Rottenstreich and Hsee 2001; Sunstein 2002; Suter et al. 2016). However, the model could be extended by multiplying each $\phi$ by a weighting function $w\left(p_{i}\right)$ that can be a nonlinear function of probabilities (e.g., overweighting lowprobability events, but not assigning equal weights to all outcomes) or depend on the "vividness" of the outcome (Loewenstein 1987).
} 
$(3)\left(\frac{1}{20}\right)((2)(-100))=-25$. Thus, adding in anticipatory emotions has increased risk-aversion, since now the gamble has an even more negative expected utility, $U=(-25)+(-50)=-75$. If we allow for anticipatory emotions but assume that $\sigma=1$ with equal weight on positive and negative anticipatory emotions, then $U_{A}=\sum \phi\left(v\left(x_{i}\right)\right)=\left(\frac{1}{20}\right)(100)+(1)\left(\frac{1}{20}\right)((2)(-100))=$ -5 , and thus $U=(-5)+(-50)=-55$. That is, loss-aversion with only consumption utility implies some risk-aversion for mixed gambles; adding in anticipatory utility implies additional riskaversion even if we assume that negative and positive anticipatory emotions are equally strong, $\sigma=1$; and assuming that negative anticipatory emotions are stronger, $\sigma>1$, implies even more risk-aversion. Thus, each source of dread-aversion is associated with additional risk-aversion. An equivalent formulation of this point is that time delay increases risk-aversion for mixed gambles, since anticipatory (dis)utility is accrued only when there is delay.

Next, we show that dread-aversion also implies impatience. Let's now assume that instead of representing a discrete time point, anticipatory utility is accumulated continuously over a timeinterval of length $T$, reflecting the delay between $T_{0}$ and $T_{2}$. We assume that consumption and anticipatory utility have a common discount factor $\gamma$, where $0<\gamma<1$ and $0<t \leq T$. Then the expected (discounted) consumption utility is:

$$
U_{C}=\sum_{i} v\left(x_{i}\right) \pi\left(p_{i}\right) \gamma^{T}
$$

Based on prior behavioral work (Berns et al. 2006; Iigaya et al. 2016; Story et al. 2015), we assume that anticipation grows stronger as an event approaches. Thus, discounted anticipatory utility is:

$$
U_{A}=\int_{0}^{T} \sum_{i} \phi\left(v\left(x_{i}\right)\right) e^{-z(T-t)} \cdot \gamma^{t} d t
$$

where $0<z<1$ controls the rate at which anticipation grows stronger.

In this model, utility declines more steeply as $\sigma$ increases, reflecting increasing impatience with greater dread-aversion. To see this, consider the derivative of $U=U_{A}+U_{C}$ with respect to time:

$$
\left.\frac{\partial U}{\partial t}\right|_{t=T}=\gamma^{T} \sum_{i} \phi\left(v\left(x_{i}\right)\right)+v\left(x_{i}\right) \pi\left(p_{i}\right) \ln \gamma
$$

Negative values of $\left.\frac{\partial U}{\partial t}\right|_{t=T}$ correspond to greater impatience in the sense of preferring outcomes to occur sooner. The $\sigma$ parameter only appears through $\phi\left(v\left(x_{i}\right)\right)$ and only for terms where $x_{i}<$ 0 . These terms are all negative because $v$ and $\phi$ are increasing functions, with $v(0)=0$ and $\phi(0)=0$. Therefore, $\left.\frac{\partial U}{\partial t}\right|_{t=T}$ becomes more negative as $\sigma$ increases, showing that dread-aversion implies greater impatience. 
Intuitively, this happens because greater $\sigma$ corresponds to higher levels of anticipatory disutility, which accumulates as the interval increases in length $T$. Assume we are faced with a coin flip gamble which we can choose to resolve immediately, $T=0$, or after a delay, $T=1$. Tails always results in a loss of $-\$ 50$, while heads pays $+\$ 105$ immediately or $+\$ 110$ with the delay. Assume that $\gamma=0.9, z=0.8$, and $\lambda=2$. First, let's assume there is no dread-aversion, $\sigma=1$. For the immediate option, the total utility would equal $[(0.5)(105)+(0.5)(2)(-50)]\left(0.9^{0}\right)=$ +2.5 , since there is only consumption and no anticipation utility. For the delayed option, the consumption utility would be higher, $[(0.5)(110)+(0.5)(2)(-50)]\left(0.9^{1}\right)=+4.5$, reflecting the higher expected value of the gamble, and the anticipation utility would be slightly positive, $\left[\left(\frac{1}{20}\right)(110)+(1)\left(\frac{1}{20}\right)((2)(-50))\right] \int_{0}^{1} e^{-(0.8)(1-t)}(0.9)^{t} d t=(0.50)(0.65)=+0.33$. This leads to higher total utility, +4.83 , for the larger, delayed option. However, if we add in dreadaversion, $\sigma=3$, this leads to negative anticipatory utility for the delayed option,

$\left[\left(\frac{1}{20}\right)(110)+(3)\left(\frac{1}{20}\right)((2)(-50))\right] \int_{0}^{1} e^{-(0.8)(1-t)}(0.9)^{t} d t=(-9.50)(0.65)=-6.18$, so that the total utility for the delayed option, -1.68 , is now smaller than for the immediate option.

Thus, adding in dread-aversion can generate a preference reversal toward impatient choices. An equivalent formulation of this point is that uncertainty increases impatience for mixed gambles, since anticipatory (dis)utility is accrued only when there is uncertainty. To the extent there is uncertainty attached to any future prospect (as only immediate consequences can be totally certain), dread aversion explains why individuals in standard time discounting models have such a strong preference for certain immediate smaller rewards than "certain" larger future rewards (Loewenstein and Prelec 1992). In this view, it seems reasonable that people prefer $\$ 100$ immediately over $\$ 120$ in a weeks' time but also prefer $\$ 120$ in a year and one weeks' time over $\$ 100$ in a years' time, as in hyperbolic discounting.

\section{Empirical Evidence}

\section{Estimating Dread Aversion}

We first test whether the anticipation of future losses and gains are direct sources of (dis)utility, as in Loewenstein (1987), and whether dread is more powerful than savoring (dread aversion) as Hardisty and Weber (2020) find in their lab studies.

To measure an individual's intrinsic anticipatory reactions to contemplating future losses (dread) and future gains (savoring), we use a simple approach which looks at how individuals' current forecasts about next year's financial circumstances affects their current psychological well- 
being. To the extent one is dread-averse, forecasting financial losses should have a greater effect on current psychological well-being compared to forecasting gains. Thus, this is conceptually distinct from loss aversion (Kahneman and Tversky 1979), which reflects the (asymmetric) relationship between current well-being and realized losses and gains.

To implement this strategy, we use data from the British Household Panel Survey (BHPS), a longitudinal survey measuring a wide variety of economic, social, and psychological variables among a nationally representative sample of over 5,000 UK households. The BHPS consists of 18 annual waves of data from 1991 to 2008. The sample used for the subsequent analysis is restricted to the first 17 waves of data (Waves 1-17) and to the original BHPS sample covering Great Britain. This yields a sample size of 122,923 observations from 13,821 individuals. Therefore, intrinsic anticipatory emotions are constructed from an average of 8.9 observations per individual.

Financial forecasts were measured in each wave ("Looking abead, how do you think you yourself will be financially a year from now; better than you are now, worse than you are now, or about the same?'). Psychological well-being was measured using the General Health Questionnaire $(G H Q)$ measured in each wave, a 12-item scale measuring psychological distress or 'disutility' (e.g., "Have you recently lost much sleep over worry?' and 'Have you recently been feeling reasonably happy all things considered?" [reversecoded]). Responses are coded on a 4-point scoring system (items scored 0-1-2-3) that ranges from "strongly disagree" to "strongly agree". Scores are then summed together, providing each respondent with a total GHQ score ranging from 0-36, with higher scores corresponding to lower psychological well-being or higher 'disutility'.

We assess the relationship between financial forecasts $(F)$ and disutility $(G H Q)$, by estimating the following linear random effects multilevel equation for the ith individual at time $t$ :

$$
\begin{gathered}
G H Q_{i t}=b_{0}+b_{1} F_{i t}^{\text {Better }}+b_{2} F_{i t}^{\text {Worse }}+b_{3} \bar{F}_{i}^{\text {Better }}+b_{4} \bar{F}_{i}^{\text {Worse }}+b_{5} X_{i t}+b_{6} \bar{X}_{i}+z_{i 0}+ \\
z_{i 1} F_{i t}^{\text {Better }}+z_{i 2} F_{i t}^{\text {Worse }}+\varepsilon_{i t}
\end{gathered}
$$

where, $F_{i t}^{\text {Better }}$ is a dummy variable indicating a financial expectations of "better off" (for time $t+1$ ) at time $t$ (i.e. $F_{i t}^{\text {Better }}=1$ if the respondent expects to be "better off", otherwise $\left.F_{i t}^{\text {Better }}=0\right) . F_{i t}^{\text {Worse }}$ is a dummy variable indicating a financial expectation of "worse off" (i.e., $F_{i t}^{\text {Worse }}=1$ if the respondent expects to be "worse off", otherwise $F_{i t}^{\text {Worse }}=0$ ), therefore a forecast of "about the same" serves as a baseline category to which the other forecasts are compared. $X_{i t}$ is a vector of time-varying sociodemographic and socioeconomic control variables. To constrain all the variation to within-person, we follow Mundlak (1978), by including the time means of all the time-varying independent variables-that is, $\bar{F}_{i}^{\text {Better }}, \bar{F}_{i}^{\text {Worse }}$, and $\bar{X}_{i}$. Therefore, $b_{1}$ and $b_{2}$ represent the average within-person effects of $F_{i t}^{\text {Better }}$ and $F_{i t}^{\text {Worse }}$, respectively. To 
allow individuals to have different psychological responses to expected income, we include both a random effect $\left(z_{i 0}\right)$ attached to the intercept and a random effect $\left(z_{i 1}\right.$ and $\left.z_{i 2}\right)$ attached to the within-person coefficients. These random effects together allow us to estimate heterogeneity in the within-person effect of $F_{i t}^{\text {Better }}$ and $F_{i t}^{\text {Worse }}$ across individuals. Specifically, $z_{i 1}$ and $z_{i 2}$ reflects the difference between the average within-person effect of anticipatory emotions, $b_{1}$ and $b_{2}$, and the effect for each individual. We estimate Equation 1 with an unstructured covariance matrix to allow for correlation between the random effect attached to the intercept and the random effects attached to the within-person coefficients. The within-person errors are modelled using an autoregressive structure of order 2, which is confirmed by model selection criteria (in particular, the Akaike and Bayesian Information Criteria). The results of Equation 1 and a description of the control variables are available in Table A1 of the Appendix. ${ }^{3}$

Figure 1 depicts the heterogeneity in the magnitude of dread and savoring across individuals, by plotting the estimated random coefficient for each individual (i.e., $b_{1}+z_{i 1}$ or $b_{2}+z_{i 2}$ ), with coefficients rescaled so that measures of anticipatory reactions to future monetary losses and gains are increasing in disutility and utility, respectively. These individual effects provide estimates of intrinsic anticipatory reactions to contemplating future monetary losses (dread) and future monetary gains (savoring), net of any other environmental influences from location and time and any other changes to individual circumstance.

Figure 2 and the estimates of Equation 1 in Table A1 of the Appendix can be used to answer three questions. First, does the anticipation of future financial gains and losses generate current anticipatory (dis)utility? Despite considerable heterogeneity across individuals, the average withineffect effects of expecting to be "worse off" $\left(b_{2}=0.577,95 \% C I=[0.488,0.666], S E=\right.$ $0.045, p<.001)$ and 'better off' $\quad\left(b_{1}=-0.084,95 \% C I=[-0.153,-0.015], S E=\right.$

\footnotetext{
${ }^{3}$ We consider a barrage of robustness checks for Equation 1 which all yield results consistent with our reported analysis. Firstly, although our measure of dis(utility) approximately follows a normal distribution it shares certain characteristics of a Poisson distribution. In this view, we estimate Equation 1 with Poisson regression techniques. Secondly, although we already include an autoregressive residual error structure in our main analysis, we estimate Equation 1 as a dynamic panel model, using both a general method of movements and maximum likelihood structural equation approach. Thirdly, we consider various instrumental variable approaches to test for issues surrounding simultaneity. Our main approach for identification follows Huberman et al. (2018), where expectations are identified by having "picked" (voted for) the current governing political party. Finally, although we can never completely rule out that the estimated strength of anticipatory emotions is unbiased, the real interest is in individual differences in their prevalence and a general bias does not affect this property.
} 
$0.035, p=.017$ ) are both significantly different from zero and in the expected direction, providing evidence of both dread and savoring, consistent with Loewenstein (1987).
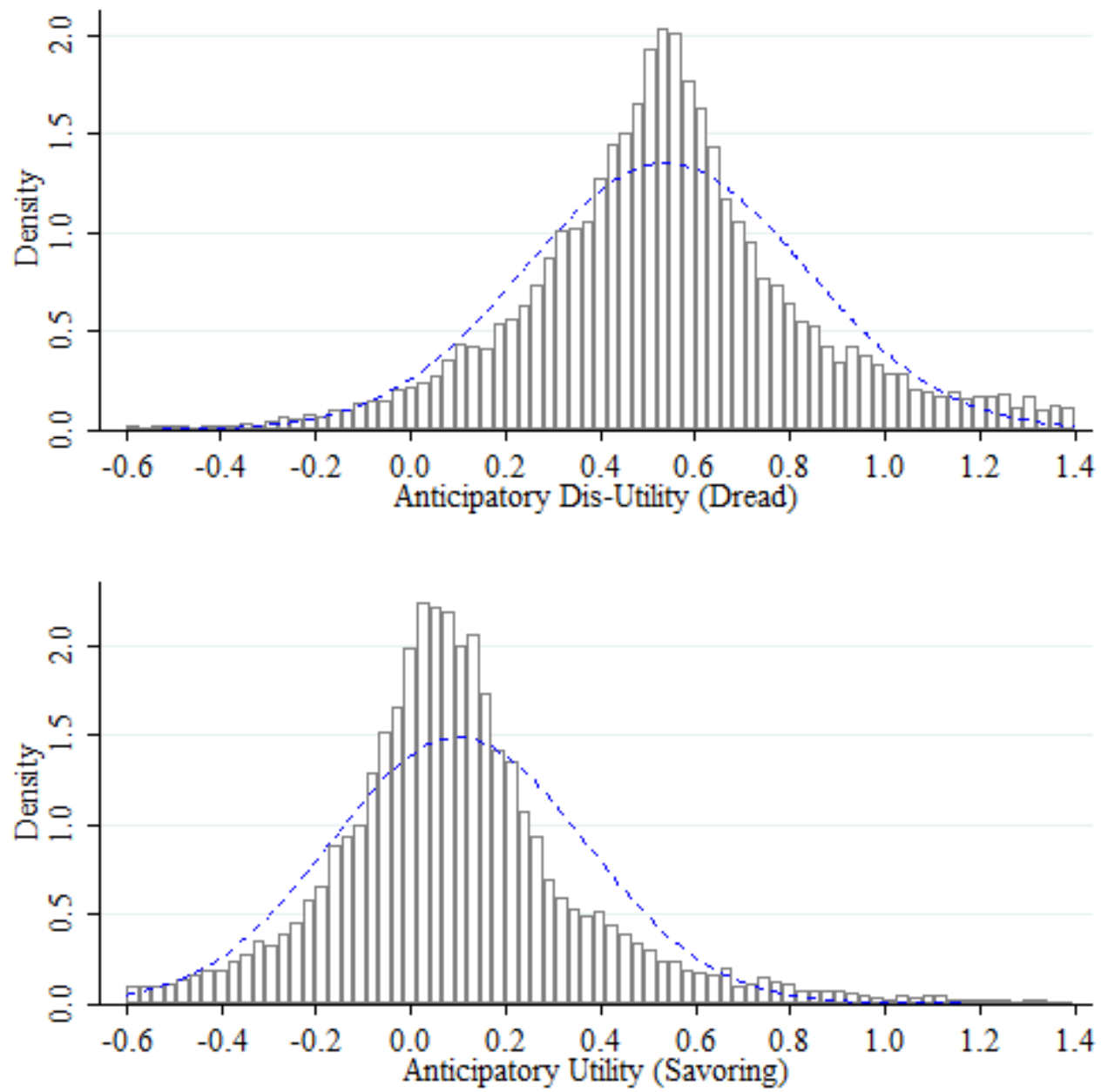

Figure 2. Histogram of individual anticipatory disutility (dread) and anticipatory utility (savoring) based on a single estimate per individual $(n=$ 13,821). A normal density is also plotted in each graph, with the same mean and variance as the estimated data.

Second, are dread and savoring equally powerful anticipatory emotions? They are not: Figure 2 and the average within-effect effects of "worse off" and "better off" discussed above makes plain that dread is much more powerful than savoring. If we define dread aversion at the group level as the ratio of the average within-person coefficients associated with dread and savoring (i.e., $b_{2} / b_{1}$ ), the mean (median) ratio is $6.87(7.62)$-greater than the typical estimate of loss aversion (a ratio of about 2; Kahneman and Tversky 1992). This accords with Hardisty and Weber's (2020) lab studies, which find substantial amounts of dread but little evidence of savoring. This also demonstrates that dread aversion is not merely a consequence of loss aversion. That is, one possible 
mechanism for dread aversion is that people experience stronger emotions in response to negative outcomes losses because they expect that their experiences of those outcomes will be more negative (i.e., they forecast that they will experience loss aversion). If this were the case, we would expect a ratio of dread to savoring of about 2 , as typical for loss aversion. Instead, the much greater ratio implies that a further mechanism is at work, consistent with Hardisty and Weber's (2020) conclusion that dread itself is a more potent emotion than savoring (even in anticipation of an equivalent emotional experience), because savoring is a mixed emotion of pleasure and impatience, whereas dread is a purely unpleasant emotion. In terms of our model, this implies that $\sigma>0$.

Third, are people higher in negative anticipatory emotions (dread) also higher in positive anticipatory emotions (savoring), as one might expect if they emanate from the common psychological mechanism of vividly imagining the future? Equation 1 estimates a negative correlation between the random effect parameters, $z_{i 1}$ and $z_{i 2}, r(13,819)=-0.494, p<.001$, suggesting that individuals higher in savoring are also higher in dread. To our knowledge, this is the first evidence that individuals who are more sensitive to positive anticipatory emotions also tend to be more sensitive to negative ones.

\section{Dread Aversion and Economic Preferences}

Next, we determine empirically whether individual differences in anticipatory emotions may be linked to risk taking and time preferences, as our theory suggests.

In estimating the effect of dread aversion on risk preferences, we use the general risk question ("Are you generally a person who is fully prepared to take risks or do you try to avoid taking risks?" from 1 ("unwilling to take risks") to 10 ("fully prepared to take risks")), which was only asked in the final wave (Wave 18) of the BHPS. The timing of the risk question ensures there is no overlap with the time periods we used to elicit individual levels of dread aversion, therefore, individual anticipatory emotions are expected to be exogenous with respect to individual risk preferences. This measure of risk has been widely validated, with Dohmen et al. (2011) suggesting it the best all-round predictor of risky behavior. Figure A1 in the Supplementary Materials shows the distribution of general risk attitudes for our sample. It is worth noting, that we do lose a significant proportion of individuals in our second-stage analysis owing to sample attrition. However, sample attrition rates in the BHPS are generally low and certainly comparable to those achieved in other similar household panels. In common with nearly all previously published research using this data source, attrition is assumed to be a random event.

Table 1 reports the key results. As risk attitudes are ordinal, we use Ordered Logistic regression, with odds ratios reported for ease of interpretation. We standardize our anticipatory emotions and 
include controls for gender and an assortment of other personal characteristics and socioeconomic and sociodemographic variables, which are described in Table 1. As shown in Table 1, conditional on savoring and the controls, dread has a negative effect on risk, while savoring has a positive effect. Specifically, a 1 SD increase in dread is associated with 0.738 lower proportional odds of being in the highest risk-taking category (versus the combined other categories), whereas a $1 \mathrm{SD}$ increase in savoring is associated with 1.201 higher odds. Mirroring prior work, women are more risk-averse than men (Charness \& Gneezy, 2012; Dohmen et al., 2011; Eckel \& Grossman, 2002). Using Shapley-based decompositions we also report the relative importance of anticipatory emotions for risk preferences. The Shapley-based decomposition method extracts the separate contribution to the explained variation in risk preferences of each included independent variable. From Table 1, gender (an important predictor of risk) explains 10.15\% of the explained variation in risk, whereas anticipatory emotions jointly contribute $8.94 \%$ with dread more important $(7.03 \%)$ than savoring (1.91\%). To the extent to which people will focus on the potential costs of a gamble, it is unsurprising that dread is the predominant emotion as implied by our model.

Table 1.

Ordered Logit Regressions Measuring the Impact of Dread Aversion on General Risk. Attitudes Dependent variable: Willingness to take risks in general

\begin{tabular}{|c|c|c|c|c|c|c|}
\hline \multirow[b]{3}{*}{ Predictors } & \multicolumn{6}{|c|}{ Dependent variable: Willingness to take risks in general } \\
\hline & \multirow[b]{2}{*}{$\beta$} & \multirow[b]{2}{*}{$O R$} & \multirow[b]{2}{*}{$t$} & \multicolumn{2}{|c|}{$95 \% \mathrm{CI}$} & \multirow[b]{2}{*}{ Shapley } \\
\hline & & & & Low & High & \\
\hline Standardized Dread & -0.304 & 0.738 & $-9.150^{* * *}$ & -0.369 & -0.239 & 7.025 \\
\hline Standardized Savoring & 0.183 & 1.201 & $5.970 * * *$ & 0.123 & 0.243 & 1.913 \\
\hline Female & -0.349 & 0.706 & $-5.350 * * *$ & -0.477 & -0.221 & 10.148 \\
\hline Pseudo R-squared & 0.0355 & & & & & \\
\hline$n$ & 6,526 & & & & & \\
\hline
\end{tabular}

Note: To account for the fact that our "Dread" and "Savoring" variables are generated, rather than observed, we generate 1000 bootstrap replicates of the regression coefficients. We use a nonparametric bootstrap procedure which draws bootstrap samples from the clusters (random samples with replacement) and puts them through the multiple stage-procedure. All regressions included the additional control variables: age (in linear form), height (cm's), logarithm of monthly household income (deflated) for the current year, current education level (highest academic qualification), current marital status, square root of current household size, number of children under the age of 16 present in the household and a series of dummy variables for current labor market status. We also include a control for current level of psychological well-being. This control was constructed as the individual's current self-reported GHQ score minus the individual's dispositional GHQ score, as measured by the fixed effects, $u_{i}$, from the following fixed effects OLS regression estimated for the sample utilized in Equation (1): $G H Q_{i t}=b_{0}+b_{1} F_{i t}^{\text {Better }}+$ $b_{2} F_{i t}^{\text {Worse }}+b_{3} X_{i t}+u_{i}+\varepsilon_{i t}$. Full results are available in Table A2 of the Appendix. 
In estimating the effect of dread aversion on time preferences, we operationalize patience as an individual's tolerance for delayed gratification — to resist the temptation of an immediate reward in preference for a later reward. We use data from Understanding Society, the UK Household Longitudinal Study (Usoc). Usoc consists of 9 annual waves of data from 2009 to 2019, with the sample consisting of over 6,000 participants from the BHPS which ended in 2008. In Wave 5 (2013), all adults completed a 10-item delayed gratification scale $(\alpha=0.66)$, taken from a longer scale (Hoerger et al., 2011). Items include "I would have a hard time sticking with a special, healthy diet" [reverse-coded]; "I cannot motivate myself to accomplish long-term goals" [reverse-coded]; "I have given up physical pleasure or comfort to reach my goals"; and "I cannot be trusted with money" [reverse-coded], all on 0 ("strongly disagree") to 10 ("strongly agree") scales. Again, the timing of the patience questions assures there is no overlap with the time periods we used to elicit individual levels of dread aversion, therefore, individual anticipatory emotions are expected to be exogenous with respect to individual time-preferences. Figure A2 in the Appendix shows the distribution of patience for our sample.

Table 2.

Ordinary Least Squares (OLS) Regressions Measuring the Impact of Dread Aversion on Delayed Gratification (Patience)

\begin{tabular}{lccccc}
\hline \multicolumn{5}{c}{ Dependent variable: Standardized Delayed Gratification Scale } \\
\hline & & & \multicolumn{2}{c}{$95 \%$ CI } & \\
\cline { 4 - 5 } Predictors & $\beta$ & $t$ & Low & High & Shapley \\
\hline Standardized Dread & -0.210 & $-9.940^{* * * *}$ & -0.251 & -0.168 & 16.269 \\
Standardized Savoring & 0.142 & $7.200^{* * *}$ & 0.103 & 0.180 & 5.910 \\
Female & 0.260 & $5.840^{* * *}$ & 0.172 & 0.347 & 6.158 \\
\hline R-squared & 0.0985 & & & & \\
$n$ & 3,979 & & & & \\
\hline
\end{tabular}

Note: See notes for Table 1. Full results are available in Table A3 of the Appendix.

Table 2 reports the key results. As time preferences are approximately linear and normally distributed, we use Ordinary Least Squares (OLS) regression. We standardize our measure of time preferences and our measures of anticipatory emotions and include the same set of controls used in Table 1. As shown in Table 2, conditional on savoring and the controls, dread has a negative effect on patience, while savoring has a positive effect. More specifically, a 1 SD increase in dread lowers patience by $0.210 \mathrm{SDs}$, whereas a $1 \mathrm{SD}$ increase in savoring increases patience by 0.142 SDs. Women tend to be more patient, as in prior work (e.g., Dittrich and Leipold 2014). From Table 2, using a Shapley-based decomposition method, gender explains $6.16 \%$ of the explained variation in patience, whilst anticipatory emotions jointly contribute $22.18 \%$ with the effect of dread (16.27\%) again outweighing savoring (5.91\%). Thus, dread aversion explains more variance 
in time preferences than in risk preferences. This may be because dread aversion reflects that anticipations of positive outcomes are mixtures of positive (savoring) and negative (impatience) emotions (Nowlis et al. 2004)—thus, dread aversion is conceptually linked to impatience.

\section{Discussion}

We gain utility not only from consuming experiences, but from anticipating our consumption. But all anticipatory emotions are not created equal. This article presents the first largescale econometric evidence that dread of imagined bad futures predominates over savoring of imagined good futures-most people are dread-averse. We further show that dread-aversion is linked to riskaversion and to impatience. Our model explains why: Dread-aversion leads downside risks to loom larger and leads delays to be more emotionally aversive. Thus, we provide a unified explanation for why these economic preferences are correlated and suggestive evidence for this explanation.

These findings make several theoretical contributions. First, both economic preferences and personality traits have been criticized as lacking a grounding in deeper psychological processes (Almlund et al. 2011). We show that, in part, risk- and time-preferences are grounded in basic psychological processes of emotion and affective forecasting, linking behavioral economics to affective and cognitive science (e.g., Berns et al. 2006; Johnson et al. 2020).

Second - given that most decisions involve both some delay and some risk-our proposal for why dread aversion unifies risk- and time-preferences suggests explanations for other phenomena about economic preferences (e.g., as reviewed in Loewenstein and Prelec 1992). As Hardisty and Weber (2020; see also Molouki et al. 2019) argue, dread aversion explains why people discount gains at a faster rate than losses-the sign effect (Thaler 1981). Since contemplating future losses produces negative affect, we are less prone to delay those losses than we would be without anticipation, decreasing the discount rate; the corresponding positive affect from contemplating gains is weaker, so discount rates remain high.

Dread and savoring can also explain the certainty effect in risky choice-for example, a much larger willingness to pay to reduce a risk from $1 \%$ to $0 \%$ than from $2 \%$ to $1 \%$, or conversely a much larger willingness to pay to increase the chance of a benefit from $0 \%$ to $1 \%$ rather than $1 \%$ to $2 \%$, despite these pairs of improvements having the same expected value (e.g., Kahneman and Tversky 1979). This follows immediately from the idea that even a small probability of a bad effect licenses savoring and dread, which are absent entirely when the event has a $0 \%$ probability. Decisions are often more sensitive to whether something is possible rather than its probability (Loewenstein et al. 2001). Dread aversion makes the further prediction that the certainty effect would be larger for losses than for gains, since the disutility associated with dread (and hence the 
utility of paying to reduce a risk to $0 \%$ ) is higher than the corresponding utility for savoring. Given the large literatures on both probability weighting and on gains/loss asymmetries, it is surprising that little work appears to have tested this prediction. However, Verschoor and D'Exelle (2020) find exactly this pattern in their elicited probability weighting functions among Ugandan farmershighly nonlinear probability weights for losses, but weights for gains that are very close to expected utility theory.

We noted in our theory section that our model implies that, for mixed gambles, time-delay increases risk-aversion and uncertainty increases impatience. If we consider the implications for non-mixed gambles, our model sheds light on a recent empirical puzzle (Hardisty and Pfeffer 2017): If the present is certain, then people are more impatient if the future is uncertain rather than certain, for both gains and losses. Prospect theory predicts risk-seeking for losses and riskavoidance for gains because of diminishing sensitivity (in consumption utility) to both losses and gains, so this effect is consistent with prospect theory for gains but not for losses. However, dreadaversion provides a clear explanation for this finding by adding in anticipatory utility. The anticipatory utility for gains is small due to modest savoring, so the usual prospect theory analysis holds. But the anticipatory disutility for losses is large due to dread, leading to a preference for certain losses in the present rather than the future gamble. Future work might look at the timecourse of savoring and dread over longer versus shorter delays, which might further moderate the effect, for instance if savoring and dread are more symmetric over shorter intervals.

Third, dread aversion makes novel predictions that can be tested in future work. Whereas Hardisty and Pfeffer (2017) look at the consequences of introducing delay to either the certain or uncertain element of a gamble, we can also consider the likely consequences of adding delay to both elements. One potentially interesting prediction concerns the magnitudes of the gain/loss asymmetry in risk-seeking from prospect theory. Because the value function is concave for gains and convex for losses, prospect theory implies that people are typically risk-averse for gains and risk-seeking for losses. However, as a choice to adopt a risky prospect in the future produces (certain) anticipatory emotions as well as (probabilistic) consumption utility, the expected psychological value of a future prospect depends on both value functions-and as we noted earlier, we know little about the shape of the value function for anticipatory utility, except that, due to dread aversion, it is steeper for losses than for gains. Dread aversion thus implies that loss aversion should be larger for delayed rather than immediate prospects - a possibility which has not been tested as far as we know. Depending on the curvature of the value function $\phi(v(x))$ for anticipatory utility, this may also affect risk-aversion asymmetrically for gains and losses. For example, for ranges where $\phi$ is relatively elastic, dread aversion implies that adding anticipatory 
utility "straighten out" the value function more for losses than for gains, leading to significantly less risk-seeking for losses, and only somewhat less risk-aversion for gains. Intuitively, this happens because dread aversion makes a certain smaller loss relatively more appealing compared to an uncertain larger loss, whereas the converse effect (savoring for uncertain gains) is weaker.

In addition to these basic directional predictions, the fact that people differ sharply in the extent of their dread aversion suggests that eliciting dread aversion for individual participants can lead to a rich variety of predictions to test about the magnitudes of these intertemporal and risky choice phenomena. If the explanations above are correct, then dread-averse (vs. "dread-neutral") people will (i) show a larger discounting asymmetry between gains and losses (the sign effect), (ii) have more nonlinear probability weighting functions (the certainty effect), but only for losses, (iii) be more loss-averse, but only for delayed prospects, and (iv) have less elastic value functions (i.e., less concave for gains and less convex for losses), but only for delayed prospects.

Disentangling anticipatory from reactive emotions leads to interesting questions about affective forecasting. For example, people overestimate the extent of loss aversion (Kermer et al., 2006) in the sense that they forecast, prior to a decision, that realized losses will be much more aversive than realized gains are pleasant, whereas the true asymmetry is smaller. Potentially, this could be due to participants' factoring in anticipatory (dis)utility experienced prior to the outcome being revealed. Since dread is stronger than savoring, expected anticipatory emotions enhance forecasts about losses more than for gains. If so, then affective forecasting errors should be larger for vivid outcomes or over longer delays. A related question is whether dread aversion itself might be an affective forecasting error. Since decisions, including risk and time preferences, depend on expected emotions rather than experienced emotions, our model does not require that expectations about emotions be rational. However, since neural evidence points to the aversive experience of dread (e.g., Berns et al., 2006), some degree of expected dread aversion is probably rational, even if it proves exaggerated in forecasts.

In addition to these theoretical implications and future research directions, these results have potential practical value. In health economics, our results suggest that dread-averse people may be less willing to seek out information that is dread-inducing, leading to less preventative care and thus higher long-term costs-for example, would people with potential HIV exposure be likelier to get tested if results were instantaneous rather than requiring 3 weeks (cf. Ganguly and Tasoff 2017)? In marketing, dread aversion may help to explain the powerful effects of promotion-focus (motivation to bring about good outcomes) versus prevention-focus (motivation to avoid bad outcomes), which differ both across situations and individuals and have important consequences for the success of marketing appeals (Avnet and Higgins 2006). In finance, dread aversion likely 
pushes investors toward safer investments, which is one potential explanation for the equity premium puzzle (Caplin and Leahy 2001) and suggests that dread-neutral investors can capitalize on this mispricing without the emotional cost taken by more dread-averse investors. Likewise, in labor markets, more dread-averse employees would favor payment structures with lower uncertainty. For strategic management and entrepreneurship, our results suggest that dread-averse decision-makers are likely to make more conservative decisions, which may be more or less desirable depending on the firm's industry, size, competitive positioning, and asset profile. Dreadaversion may indeed be a fundamental individual determinant of economic preferences on par with loss-aversion. 


\section{References}

Almlund, M., Duckworth, A. L., Heckman, J., \& Kautz, T. (2011). Personality psychology and economics. In E. A. Hanushek, S. Machin, \& L. Woessmann (Eds.), Handbook of the economics of education, Vol. 4 (pp. 1-181). Amsterdam, Netherlands: Elsevier.

Andreoni, J., \& Sprenger, C. (2012). Estimating time preferences from convex budgets. American Economic Review, 102(7), 3333-3356.

Anderhub, V., Güth, W., Gneezy, U., \& Sonsino, D. (2003). On the interaction of risk and time preferences: An experimental study. German Economic Review, 2(3), 239-253.

Andersen, S., Harrison, G. W., Lau, M. I., \& Rutström, E. E. (2008). Eliciting risk and time preferences. Econometrica, 76(3), 583-618.

Anderson, L. R., \& Stafford, S. L. (2009). Individual decision-making experiments with risk and intertemporal choice. Journal of Risk and Uncertainty, 38, 51-72.

Avnet, T., \& Higgins, E. T. (2006). How regulatory fit affects value in consumer choices and opinions. Journal of Marketing Research, 43(1), 1-10.

Baumgartner, H., Pieters, R., \& Bagozzi, R. P. (2008). Future-oriented emotions: Conceptualization and behavioral effects. European Journal of Social Psychology, 38, 685696.

Berns, G. S., Chappelow, J., Cekic, M., Zink, C. F., Pagnoni, G., \& Martin-Skurski, M. E. (2006). Neurobiological substrates of dread. Science, 312(5774), 754-758.

Borghans, L., Golsteyn, B. H .H., Heckman, J. J., \& Meijers, H. (2009). Gender differences in risk aversion and ambiguity aversion. Journal of the European Economic Association, 7(2-3), 649-658.

Caplin, A., \& Leahy, J. (2001). Psychological expected utility theory and anticipatory feelings. Quarterly Journal of Economics, 116(1), 55-79.

Dawson, C., \& de Meza, D. (2018). Wishful thinking, prudent behavior: The evolutionary origin of optimism, loss aversion and disappointment aversion. SSRN Working Paper Series.

Dasgupta, P., \& Maskin, E. (2005). Uncertainty and hyperbolic discounting. American Economic Review, 95(4), 1290-1299.

Dean, M., \& Ortoleva, P. (2015). The empirical relationship between nonstandard economic behaviors. Proceedings of the National Academy of Sciences, 116(33), 16262-16267.

Dittrich, M., \& Leipold, K. (2014). Gender differences in time preferences. Economics Letters, 122(3), $413-415$.

Dohmen, T., Falk, A., Huffman, D., Sunde, U., Schupp, J., \& Wagner, G. G. (2011). Individual risk attitudes: Measurement, determinants, and behavioral consequences. Journal of the European Economic Association, 9, 522-550. 
Epper, T., \& Fehr-Duda, H. (2018). The missing link: Unifying risk taking and time discounting. SSRN working paper.

Ganguly, A., \& Tasoff, J. (2017). Fantasy and dread: The demand for information and the consumption utility of the future. Management Science, 63, 4037-4060.

Golman, R., Gurney, N., \& Loewenstein, G. (2020). Information gaps for risk and ambiguity. Psychological Review. Advance online publication.

Hardisty, D. J., \& Pfeffer, J. (2017). Intertemporal uncertainty avoidance: When the future is uncertain, people prefer the present, and when the present is uncertain, people prefer the future. Management Science, 63, 519-527.

Harris, C. R. (2011). Feelings of dread and intertemporal choice. Journal of Behavioral Decision Making, 25(1), 13-28.

Heilman, R. M., Crisan, L. G., Houser, D., Miclea, M., \& Miu, A. C. (2010). Emotion regulation and decision making under risk and uncertainty. Emotion, 10(2), 257-265.

Hoerger, M., Quirk, S. W., \& Weed, N. C. (2011). Development and validation of the Delaying Gratification Inventory. Psychological assessment, 23, 725-738.

Huberman, G., Konitzer, T., Krupenkin, M., Rothschild, D., \& Hill, S. (2018). Economic expectations, voting, and economic decisions around elections. AEA: Papers and Proceedings. 108, 597-602.

Iigaya, K., Story, G. W., Kurth-Nelson, Z., Dolan, R. J., \& Dayan, P. (2016). The modulation of savouring by prediction error and its effects on choice. eLife, 5, e13747.

Johnson, S. G. B., Bilovich, A., \& Tuckett, D. (2020). Conviction narrative theory: A theory of choice under radical uncertainty. Psy ArXiv working paper.

Kahneman, D., \& Tversky, A. (1979). Prospect theory: An analysis of decision under risk. Econometrica, 47(2), 263-292.

Kahneman, D., \& Tversky, A. (1992). Advances in prospect theory: Cumulative representation of risk and uncertainty. Journal of Risk and Uncertainty, 5, 297-323.

Keren, G., \& Roelofsma, P. (1995). Immediacy and certainty in intertemporal choice. Organizational Behavior and Human Decision Processes, 63(23), 287-297.

Kermer, D. A., Driver-Linn, E., Wilson, T. D., \& Gilbert, D. T. (2006). Loss aversion is an affective forecasting error. Psychological Science, 17(8), 649-653.

Kocher, M. G., Krawczyk, M., \& van Winden, F. (2014). 'Let me dream on!' Anticipatory emotions and preference for timing in lotteries. Journal of Economic Behavior and Organization, 98, 29-40.

Laibson, D. (1997). Golden eggs and hyperbolic discounting. Quarterly Journal of Economics, 112(2), $443-477$. 
Loewenstein, G. (1987). Anticipation and the valuation of delayed consumption. Economic Journal, 97, 666-684.

Loewenstein, G., \& Lerner, J. S. (2003). The role of affect in decision making. In R. J. Davidson, K. R. Scherer, \& H. H. Goldsmith (Eds.), Series in affective science. Handbook of affective sciences (p. 619642). New York, NY: Oxford University Press.

Loewenstein, G., \& Prelec, D. (1992). Anomalies in intertemporal choice: Evidence and an interpretation. Quarterly Journal of Economics, 107(2), 573-597.

Loewenstein, G., Weber, E. U., Hsee, C. K., \& Welch, N. (2001). Risk as feelings. Psychological Bulletin, 127(2), 267-286.

Loomes, G., \& Sugden, R. (1982). Regret theory: An alternative theory of rational choice under uncertainty. Economic Journal, 92, 805-824.

Lovallo, D., \& Kahneman, D. (2000). Living with uncertainty: Attractiveness and resolution timing. Journal of Behavioral Decision Making, 13, 179-190.

Mellers, B., Schwartz, A., \& Ritov, I. (1999). Emotion-based choice. Journal of Experimental Psychology: General, 128, 332-345.

Molouki, S., Hardisty, D. J., \& Caruso, E. M. (2019). The sign effect in past and future discounting. Psychological Science, 30(12), 1674-1695.

Mundlak, Y. (1978). On the pooling of time series and cross section data. Econometrica, 46(1), 6985.

Nowlis, S. M., Mandel, N., \& McCabe, D. B. (2004). The effect of a delay between choice and consumption on consumption enjoyment. Journal of Consumer Research, 31(3), 502-510.

Prelec, D., \& Loewenstein, G. (1991). Decision making over time and under uncertainty: A common approach. Management Science, 37(7), 770-786.

Rottenstreich, Y., \& Hsee, C. K. (2001). Money, kisses, and electric shocks: On the affective psychology of risk. Psychological Science, 12(3), 185-190.

Story, G. W., Vlaev, I., Seymour, B., Winston, J. S., Darzi, A., \& Dolan, R. J. (2013). Dread and the disvalue of future pain. PLoS Computational Biology, 9(11), e1003335.

Story, G. W., Vlaev, I., Dayan, P., Seymour, B., Darzi, A., Dolan, R. J. (2015). Anticipation and choice heuristics in the dynamic consumption of pain relief. PLOS Computational Biology, 11(3), e1004030.

Sunstein, C. R. (2002). Probability neglect: Emotions, worst cases, and law. Yale Law Review, 112(1), 61-107.

Suter, R. S., Pachur, T., \& Hertwig, R. (2016). How affect shapes risky choice: Distorted probability weighting versus probability neglect. Journal of Behavioral Decision Making, 29(4), 437-449. 
Sutter, M., Kocher, M. G., Glätzle-Rützler, D., \& Trautmann, S. T. (2013). Impatience and uncertainty: Experimental decisions predict adolescents' field behavior. American Economic Review, 103(1), 510-531.

Thaler, R. (1981). Some empirical evidence on dynamic inconsistency. Economics Letters, 8, 201-7. 


\section{Supplementary Appendix}

Table A1.

Multilevel Regressions Showing the Effects of Financial Forecasts on Psychological Well-Being

\begin{tabular}{|c|c|c|c|c|}
\hline \multirow[b]{3}{*}{ Predictor } & \multicolumn{4}{|c|}{$\begin{array}{l}\text { Dependent Variable: General Health Questionnaire - } \\
\text { 36 Point Scale }\end{array}$} \\
\hline & \multirow[t]{2}{*}{ 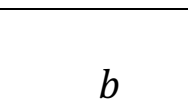 } & \multicolumn{2}{|c|}{$95 \% \mathrm{CI}$} & \multirow[b]{2}{*}{$S E$} \\
\hline & & Low & High & \\
\hline \multicolumn{5}{|c|}{ Financial Expectations: } \\
\hline$F_{i t}^{B e t t e r}$ & -0.084 & -0.153 & -0.015 & $0.035^{* *}$ \\
\hline$F_{i t}^{W o r s e}$ & 0.577 & 0.488 & 0.666 & $0.045^{* * *}$ \\
\hline \multicolumn{5}{|c|}{ Random-effects parameters: } \\
\hline$\sigma_{z 0}$ & 2.922 & 2.863 & 2.982 & $0.030 * * *$ \\
\hline$\sigma_{z 1}$ & 1.023 & 0.896 & 1.169 & $0.069 * * *$ \\
\hline$\sigma_{z 2}$ & 1.124 & 0.955 & 1.324 & $0.094 * * *$ \\
\hline$\rho_{z 0, z 1}$ & -0.164 & -0.237 & -0.090 & $0.038^{* * *}$ \\
\hline$\rho_{z 0, z 2}$ & 0.274 & 0.161 & 0.380 & $0.056^{* * *}$ \\
\hline$\rho_{z 1, z 2}$ & -0.494 & -0.740 & -0.133 & $0.157^{* * *}$ \\
\hline$n$ & 13,821 & & & \\
\hline$N$ & 122,923 & & & \\
\hline
\end{tabular}

$* p<.1 . * * p<.05 . * * * p<.01$.

Note: The multilevel regression is estimated with an unstructured covariance matrix to allow for correlation between the random effect attached to the intercept and the random effects attached to the within-person coefficients. We assume the within-person errors follow an autoregressive structure of order 2. This assumption is confirmed by model selection criteria (in particular, the Akaike and Bayesian Information Criteria). The regression also includes the individual time means of all the time-varying independent variables and control variables. The control variables: age (in linear form), the logarithm of current monthly household income (deflated), current education level (highest academic qualification), current marital status, square root of current household size, number of children under the age of 16 present in the household, current labor market status, housing tenure, region of residence, year dummy variables, and lead variables for the year ahead (i.e., time $t+1$ ) in logarithm of monthly household income (deflated), education level, marital status, the square root of current household size, the number of children under the age of 16 present in the household, labor market status, housing tenure and region of residence. Full results are available on request. The random-effects parameters $\sigma_{z 0}, \sigma_{z 1}$ and $\sigma_{z 2}$ are the estimates of the random coefficient standard deviation for the intercept and the within-person coefficients "Better Off" and "Worse Off," respectively; $\rho_{z 0, z 1}$ and $\rho_{z 0, z 2}$ are the correlations between the intercept and the within-person coefficients and $\rho_{z 1, z 2}$ is the correlation between the within-person coefficients. 
Table A2.

Ordered Logit Regressions Measuring the Impact of Dread Aversion on General Risk. Attitudes

Dependent variable: Willingness to take risks in general

\begin{tabular}{|c|c|c|c|c|c|c|}
\hline \multirow[b]{2}{*}{ Predictors } & \multirow[b]{2}{*}{$\beta$} & \multirow[b]{2}{*}{$(O R)$} & \multirow[b]{2}{*}{$t$} & \multicolumn{2}{|c|}{$95 \% \mathrm{CI}$} & \multirow[b]{2}{*}{ Shapley $\%$} \\
\hline & & & & Low & High & \\
\hline \multicolumn{7}{|l|}{ Anticipatory Emotions: } \\
\hline Standardized Dread & -0.304 & 0.738 & $-9.150 * * *$ & -0.369 & -0.239 & 7.025 \\
\hline Standardized Savoring & 0.183 & 1.201 & $5.970 * * *$ & 0.123 & 0.243 & 1.913 \\
\hline \multicolumn{7}{|l|}{ Controls: } \\
\hline Age & -0.015 & 0.986 & $-5.850 * * *$ & -0.019 & -0.010 & 17.146 \\
\hline Female & -0.349 & 0.706 & $-5.350 * * *$ & -0.477 & -0.221 & 10.148 \\
\hline Height (cm’s) & 0.011 & 1.011 & $3.230 * * *$ & 0.004 & 0.017 & 9.850 \\
\hline Psychological well-being & -0.029 & 0.972 & $-5.180^{* * *}$ & -0.039 & -0.018 & 7.248 \\
\hline Log household income & 0.146 & 1.157 & $3.650 * * *$ & 0.068 & 0.224 & 6.312 \\
\hline \multicolumn{7}{|l|}{ Highest Academic Qualification: } \\
\hline University/College degree & 0.496 & 1.642 & $5.240^{* * *}$ & 0.311 & 0.682 & 11.665 \\
\hline Vocational college qualification & 0.535 & 1.708 & $5.400 * * *$ & 0.341 & 0.730 & \\
\hline A-Level & 0.329 & 1.390 & $3.850 * * *$ & 0.162 & 0.496 & \\
\hline O-Level/GCSE’s & 0.312 & 1.366 & $3.850^{* * *}$ & 0.153 & 0.471 & \\
\hline Other qualification & 0.112 & 1.119 & 1.200 & -0.071 & 0.296 & \\
\hline No qualification & - & - & - & - & - & \\
\hline \multicolumn{7}{|l|}{ Marital Status: } \\
\hline Single & - & - & - & - & - & \\
\hline Married & -0.207 & 0.813 & $-2.690 * * *$ & -0.358 & -0.056 & 7.116 \\
\hline Couple & 0.029 & 1.030 & 0.340 & -0.138 & 0.196 & \\
\hline Widowed/divorced/separated & -0.027 & 0.974 & -0.270 & -0.223 & 0.170 & \\
\hline \multicolumn{7}{|l|}{ Household Composition: } \\
\hline Number of dependent children & -0.001 & 0.999 & -0.030 & -0.071 & 0.069 & 2.298 \\
\hline Square root of current household & & & & & & \\
\hline size & 0.018 & 1.018 & 0.170 & -0.182 & 0.217 & \\
\hline \multicolumn{7}{|l|}{ Economic Activity: } \\
\hline Employee & 0.388 & 1.474 & $4.770 * * *$ & 0.229 & 0.548 & 19.280 \\
\hline Self-employed & 0.889 & 2.433 & $8.130 * * *$ & 0.675 & 1.104 & \\
\hline Unemployed & 0.401 & 1.494 & $2.370 * *$ & 0.069 & 0.733 & \\
\hline Full-time student & 0.765 & 2.150 & $4.060 * * *$ & 0.396 & 1.135 & \\
\hline Retired & 0.302 & 1.353 & $2.920 * * *$ & 0.099 & 0.505 & \\
\hline Economically inactive & - & - & - & - & - & \\
\hline Pseudo R-squared & 0.0355 & & & & & \\
\hline$n$ & 6,526 & & & & & \\
\hline
\end{tabular}

Note: To account for the fact that our "Dread" and "Savoring" variables are generated, rather than observed, we generate 1000 bootstrap replicates of the regression coefficients. We use a nonparametric bootstrap procedure which draws bootstrap samples from the clusters (random samples with replacement) and puts them through the multiple stage-procedure. 
Table A3.

Ordinary Least Squares (OLS) Regressions Measuring the Impact of Dread Aversion on Delayed Gratification (Patience)

\begin{tabular}{|c|c|c|c|c|c|}
\hline \multicolumn{6}{|c|}{ Dependent variable: Standardized Delayed Gratification Scale } \\
\hline \multirow[b]{2}{*}{ Predictors } & \multirow[b]{2}{*}{$\beta$} & \multirow[t]{2}{*}{5} & \multicolumn{2}{|c|}{$95 \% \mathrm{CI}$} & \multirow[b]{2}{*}{ Shapley $\%$} \\
\hline & & & Low & High & \\
\hline \multicolumn{6}{|l|}{ Anticipatory Emotions: } \\
\hline Standardized Dread & -0.210 & $-9.940 * * *$ & -0.251 & -0.168 & 16.269 \\
\hline Standardized Savoring & 0.142 & $7.200 * * *$ & 0.103 & 0.180 & 5.910 \\
\hline \multicolumn{6}{|l|}{ Controls: } \\
\hline Age & 0.007 & $4.040 * * *$ & 0.004 & 0.010 & 5.045 \\
\hline Female & 0.260 & $5.840^{* * *}$ & 0.172 & 0.347 & 6.158 \\
\hline Height (cm's) & 0.003 & 1.490 & -0.001 & 0.007 & 1.010 \\
\hline Psychological well-being & -0.020 & $-6.430 * * *$ & -0.027 & -0.014 & 8.947 \\
\hline Log household income & 0.082 & $2.570^{* *}$ & 0.019 & 0.144 & 6.649 \\
\hline \multicolumn{6}{|l|}{ Highest Academic Qualification: } \\
\hline University/College degree & 0.641 & $9.950 * * *$ & 0.514 & 0.767 & 30.139 \\
\hline Vocational college qualification & 0.374 & $5.320 * * *$ & 0.236 & 0.511 & \\
\hline A-Level & 0.450 & $7.280^{* * *}$ & 0.329 & 0.571 & \\
\hline O-Level/GCSE’s & 0.337 & $5.690 * * *$ & 0.221 & 0.454 & \\
\hline Other qualification & 0.202 & $2.960 * * *$ & 0.068 & 0.336 & \\
\hline No qualification & - & - & - & - & \\
\hline \multicolumn{6}{|l|}{ Marital Status: } \\
\hline Single & - & - & - & - & \\
\hline Married & 0.191 & $3.290 * * *$ & 0.077 & 0.304 & 6.814 \\
\hline Couple & 0.082 & 1.270 & -0.044 & 0.207 & \\
\hline Widowed/divorced/separated & 0.135 & $1.970 * *$ & 0.001 & 0.269 & \\
\hline \multicolumn{6}{|l|}{ Household Composition: } \\
\hline Number of dependent children & 0.036 & 1.390 & -0.015 & 0.087 & 1.124 \\
\hline Square root of current household size & -0.115 & -1.530 & -0.261 & 0.032 & \\
\hline \multicolumn{6}{|l|}{ Economic Activity: } \\
\hline Employee & 0.160 & $2.520 * *$ & 0.036 & 0.283 & 11.935 \\
\hline Self-employed & 0.357 & $4.640 * * *$ & 0.206 & 0.508 & \\
\hline Unemployed & 0.070 & 0.600 & -0.159 & 0.298 & \\
\hline Full-time student & 0.523 & $2.820 * * *$ & 0.160 & 0.886 & \\
\hline Retired & 0.246 & $3.330 * * *$ & 0.101 & 0.391 & \\
\hline Economically inactive & - & - & - & - & \\
\hline R-squared & 0.0985 & & & & \\
\hline$n$ & 3,979 & & & & \\
\hline
\end{tabular}

Note: See notes for Table A2. 


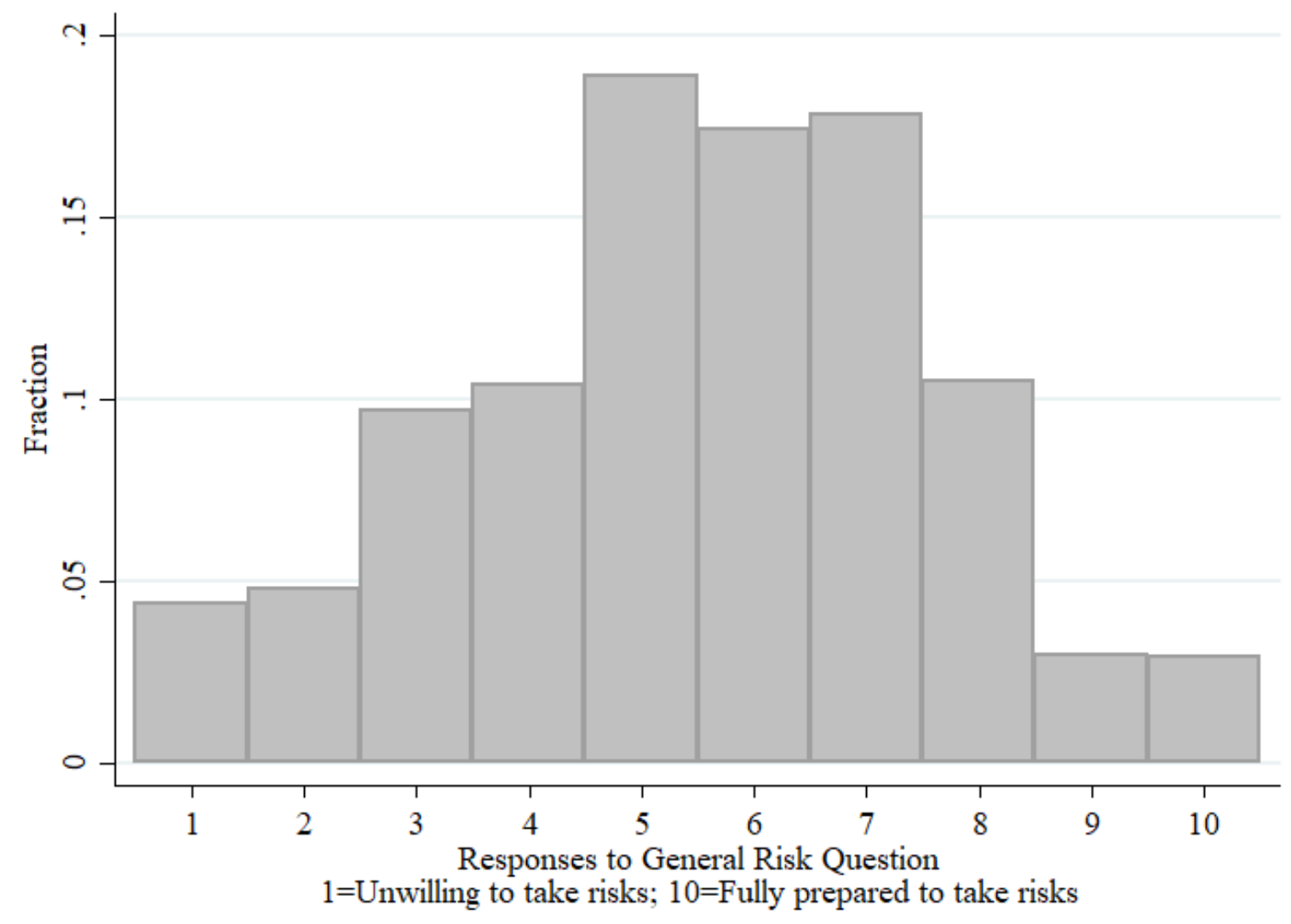

Figure A1. Histogram of responses to the General Risk Question $(n=6,526)$. 


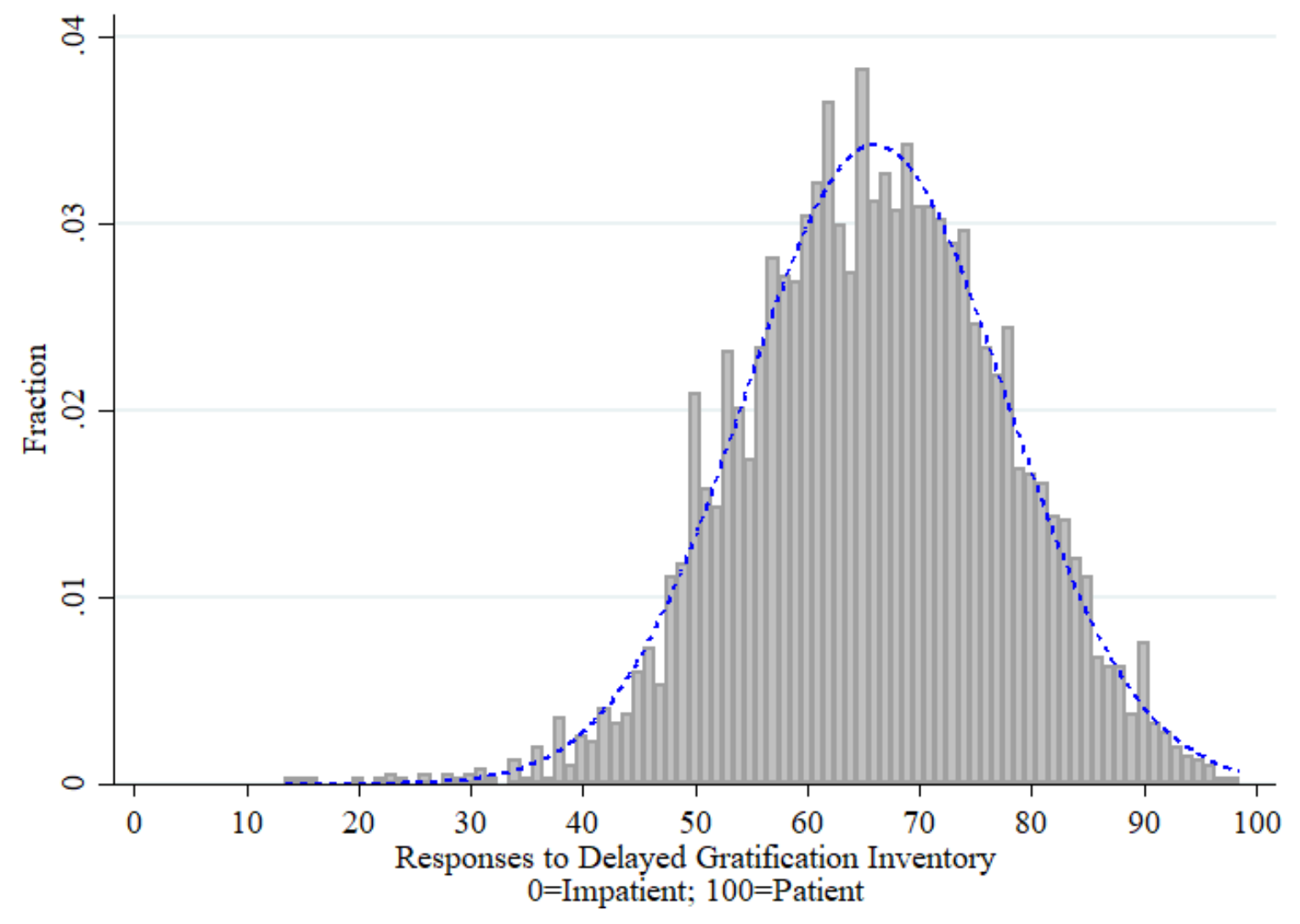

Figure A2. Histogram of responses to the Delayed Gratification Inventory $(n=3,979)$. A normal density is also plotted in each graph, with the same mean and variance as the estimated data. 